\title{
NOVA LEIDYULA BAKER DA JAMAICA (MOLLUSCA, SOLEOLIFERA, VERONICELLIDAE)
}

\section{José Willibaldo Thomé ${ }^{1}$}

\author{
ABSTRACT. NEW LEIDYULA BAKER OF JAMAICA (MOLLUSCA, \\ SOLEOLIFERA, VERONICELLIDAE). Leidyula goodfriendi, sp.n. is \\ described. \\ KEY WORDS. Mollusca, Soleolifera, Veronicellidae, Leidyula
}

Ao examinar uma coleção de lesmas para identificação, enviada pelo Dr. Glenn A. Goodfriend, do "Weizmann Institut of Sciences", de Rehovat, Israel e provenientes da Jamaica (THOMÉ, 1988c), deparei com alguns lotes atribuíveis ao gênero Leidyula Baker, 1925, que não eram determináveis para as espécies conhecidas.

$\mathrm{O}$ gênero Leidyula tem ocorrência restrita às Américas do Norte $\mathrm{e}$ Central, e Antilhas, reconhecendo-se no mesmo as seguintes espécies: Leidyula kraussi (Férussac, 1823), L. floridana (Leidy, 1851), L. moreleti (Fischer, 1871), L. portoricensis (Semper, 1885), L. dissimilis (Cockerell, 1892) e L. trichroma (Baker, 1935), segundo THOMÉ (1969, 1971, 1973, 1975, 1988a, 1988b, 1988d, 1990).

Desse modo, proponho atribuir aos espécimes em estudo um nome novo, pelo qual homenageio o coletor.

\section{Leidyula goodfriendi, sp.n.}

Figs 1-20

Diagnose. Uma Leidyula com listra irregular escura mediana longitudinal na sola; reto penetrando no tegumento algo afastado do oviducto; bolsa acessória penetrando diretamente no tegumento, à direita do canal da espermateca e sem envolver o deferente médio; pênis com soquete curto, prolongandose numa glande mais grossa, que acha-se entumescida na base como uma nervura circular.

Descrição. Forma pequena (cerca de $30 \mathrm{~mm}$ de comprimento), com noto de colorido geral marrom-cinzento, com pigmentação irregular de pontos e manchas negras, por vezes também finos pontos brancos e costumeiramente distribuidos de modo a deixarem livre uma listra mediana longitudinal e os perinotos. Hiponotos geralmente bem escuros, marrom-cinzentos, também com

1) Instituto de Biociências, Pontifícia Universidade Católica do Rio Grande do Sul, Av. Ipiranga, 6681, 90619-900 Porto Alegre, Rio Grande do Sul, Brasil. Bolsista da CAPES. 
pigmentações em manchas negras marmoradas e por vezes alguns pontos negros. Sola do pé clara, com manchas pigmentadas escuras, dispostas em uma listra irregular longitudinal mediana. Alça intestinal anterior atrás do primeiro lóbulo da glândula digestiva. $\mathrm{O}$ reto penetra no tegumento levemente afastado e para trás do oviducto (Figs $3,7,11,15,19)$. Os nervos pediosos nascem juntos e seguem juntos paralelos cerca de $1 / 4$ de seu comprimento, quando se afastam um do outro em ângulo arqueado e prosseguem afastados, paralelos, soltos até próximo do final da cavidade geral. A glândula pediosa pequena (cerca de $3 \mathrm{~mm}$ de comprimento), alargada na frente, estreita-se e apresentando então largura uniforme até a ponta; achatada, solta; diferenciada em tecido claro externo, que delimita para o meio tecido amarelado, o qual forma a totalidade da ponta, onde ocorre uma depressão central; em geral o tecido amarelado possui um curto fendilhamento longitudinal mediano (Figs 4, 8, 12, 16, 20). A espermateca globulóide, com grosso e curto canal; o curto ducto de ligação penetra no canal, mais próximo da base do que da espermateca; o vaso deferente posterior distal é tão curto quanto o ducto de ligação; o oviducto penetra no tegumento bem junto ao canal; a bolsa acessória penetra no tegumento para trás do oviducto, por um curtíssimo ducto, encontrando-se entre o oviducto e o reto (Figs 3, 7, $11,15,19)$. A glândula peniana com papila curta, afilada e túbulos em geral diferenciados em internos mais finos e externos mais grossos; os internos sempre em número menor do que os externos; podem ocorrer túbulos furcados (Figs 2, $6,10,14,18)$. O pênis curto, com soquete cilíndrico, delgado, que se prolonga em glande mais grossa, em geral de aspecto mais liso, limitado por nervura circular; a ponta da glande apresenta largo tecido cretáceo, com a abertura distal do vaso deferente (acrocaule) (Figs 1, 5, 9, 13, 17).

Localidade-tipo. Clarksonville, Cedar Valley, Saint Ann, Jamaica.

Holótipo. MCN-9291, JAMAICA: Clarksonville, Cedar Valley, Saint Ann (lado norte do morro, atrás de depressão, no lado sul da estrada 146 para Cedar Valley e a 1,1 milhas W-SW da junção com a estrada principal para Clarksonville), em 1975-2025 pés de altitude, na floresta, 14-V-1977, G.A. Goodfriend leg. Parátipos, MCN-9291a, mesmo dados do holótipo; MCN-9286, JAMAICA: Cave Valley, Greenock, Saint Ann (lado norte do morro, à 2900 pés de distância em linha reta para NE da junção para com Cave Valley), em 1900-2000 pés de altitude, na floresta, 09-IX-1980, G.A. Goodfriend leg.; GAG-SN-108, JAMAICA: Top Buxton, Muir House Pen, Saint Ann (NE de Alexandria e lado leste do morro, cerca de 1000 pés ao sul da estrada a leste e 0,6 milhas a E da junçāo com a estrada à Top Buxton), em 2300-2450 pés de altitude, na floresta, 29-IX-1976, G.A. Goodfriend leg; GAG-SN-99, JAMAICA: Middle Buxton, Saint Ann (lado este do morro no lado sul da estrada 298 para Colliston, cerca de 100 jardas a este da estrada principal e 2,1 milhas ao sul da junção com a 134 para Lower Buxton a SE de Brow's Town), 2150-2225 pés de altitude, na floresta, 20-IX-1976, G.A. Goodfriend leg.

Observação. $\mathbf{M C N}=$ Museu de Ciências Naturais da Fundação Zoobotânica do Rio Grande do Sul, Porto Alegre, RS; GAG=Coleção particular do Doutor Glenn A. Goodfriend. 

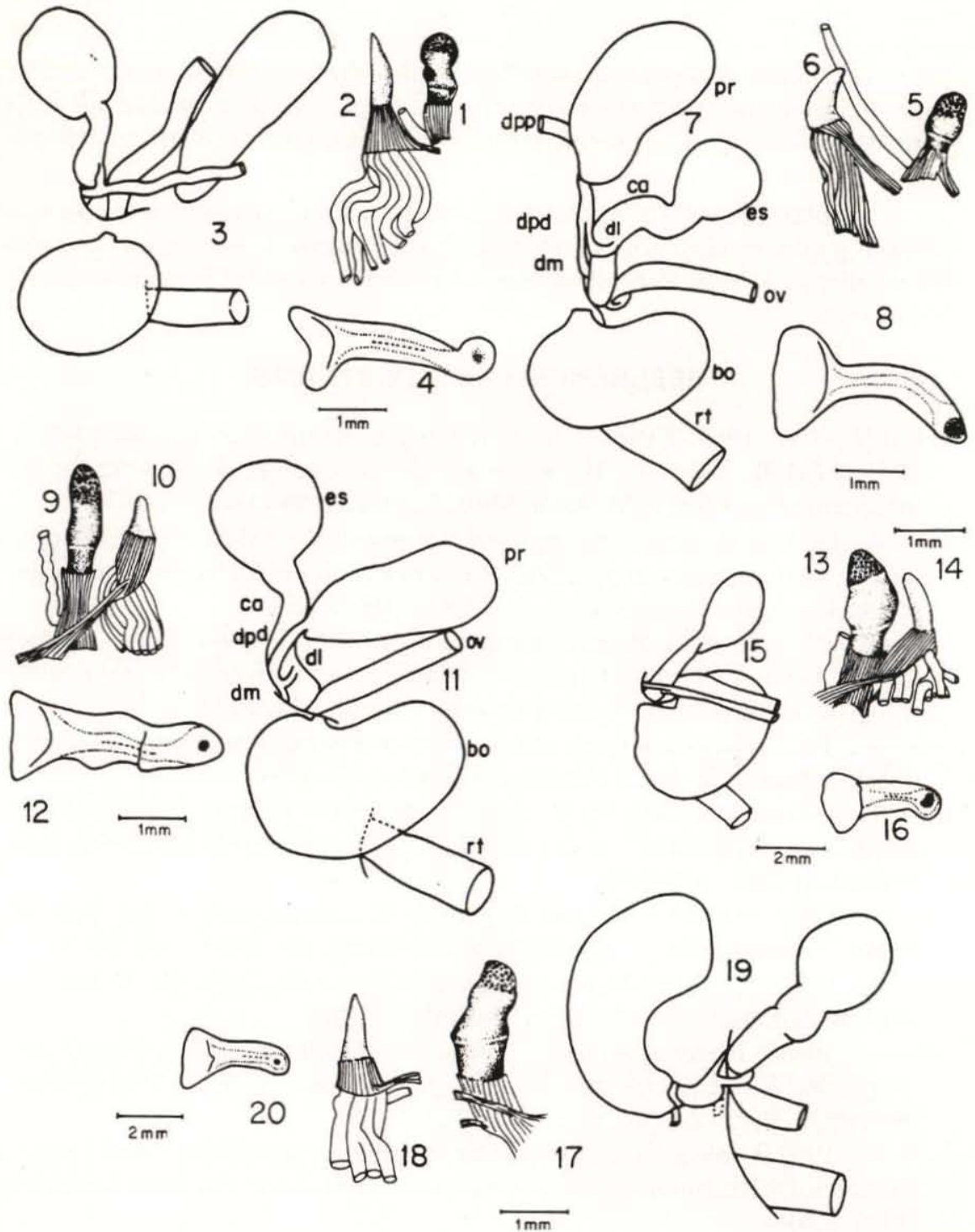

Fig. 1-20. Leidyula goodfriendi, sp.n. (1-4) Holótipo, MCN-9291. (1) Pênis; (2) glândula peniana, com túbulos truncados; (3) partes dos órgãos genitais posteriores e do reto; (4) glândula pediosa. (5-8) Parátipo, MCN-9291a. (5) Pênis; (6) glândula peniana, com túbulos truncados; (7) partes dos órgãos genitais posteriores e do reto; (8) glândula pediosa. (9-12) Parátipo, MCN-9286. (9) Pênis; (10) glândula peniana, com túbulos truncados; (11) parte dos órgãos genitais posteriores e do reto; (12) glândula pediosa. (13-16) Parátipo, GAG-SN-108. (13-14) Pênis e glândula peniana, com os túbulos truncados. (15) Parte dos órgãos genitais posteriores e do reto. (16) Glândula pediosa. (17-20) Parátipo GAG-SN-99. (17) Pênis; (18) glândula peniana, com túbulos truncados; (19) parte dos órgãos genitais posteriores e do reto (faltando a bolsa acessória, que foi destruída na dissecação); (20) glândula pediosa. 
Discussão. A espécie assemelha-se unicamente à Leidyula kraussi; diferindo da mesma por peculiaridades no pênis, na posição da bolsa acessória, na penetração do reto no tegumento e no desenho da pigmentação da sola do pé.

AGRADECIMENTOS. Ao Dr. Glenn A. Goodfriend, pelo empréstimo da coleção e por ter cedido gentilmente material para a coleção sob minha curadoria. À minha esposa Clélia pelas fotos do holótipo, à Rejane Rosa pelo acabamento dos desenhos e à Silvia Soares pela digitação do manuscrito.

\section{REFERÊNCIAS BIBLIOGRÁFICAS}

THOMÉ, J.W. 1969. Erneute Beschreibung neotropischer Veronicellidae Typen (Moll., Gastr.) - II. Arten aus der Sammlung des Senckenberg Museums Frankfurt a. M. Arch. Moll., Frankfurt, 99 (5/6): 331-363.

. 1971. Redescrição dos tipos de Veronicellidae (Moll.: Gastr.) neotropicais: VII. Espécies depositadas "Museum National d'Histoire Naturelle",

Paris. Iheringia, Porto Alegre, ser. Zool., (40): 27-52. 1973. Erneute Beschreibung neotropischer Veronicellidae - Typen (Moll., Gastr.) - VI. Artem aus der Sammlung des Universitetes Zoologiske Museum in Kopenhagen. Steenstrupia, Copenhague, 3 (4): 31-50.

— 1975. Os gêneros da família Veronicellidae nas Américas (Moll.: Gastr.). Iheringia, Porto Alegre, ser. Zool., (48): 3-56.

— 1988a. Recaracterização de Leidyula kraussi (Férussac, 1823) (Moll.; Gastr., Veronicellidae). In: Resumos do XV Congresso Brasileiro de Zoologia, Curitiba, 1988, p.30.

- 1988b. Recaracterização de Veronicella sloanei (Cuvier, 1817) (Moll.:

Gastr.: Veronicellidae). Iheringia, Porto Alegre, ser. Zool., (67): 13-35. 1988c. Lista das Veronicellidae (Mollusca: Gastropoda) da Jamaica.

Rev. Brasil. Biol., Rio de Janeiro, 48 (4): 807-810.

. 1988d. Redescrição dos tipos de Veronicellidae (Moll.: Gastr.) neo-

tropicais: XI. Espécies na "Academy of Natural Sciences", Philadelphia. Iheringia, Porto Alegre, ser. Zool., (69): 25-39.

- 1990. Uma nova Leidyula (Veronicellidae, Soleolifera, Moll.) para a Jamaica. In: Resumos do XVII Congresso Brasileiro de Zoologia, Londrina, 1990, p.448.

Recebido em 21.V.1990; aceito em 25.XI.1993. 